\title{
Brushless DC Motor Speed Controller for Electric Motorbike
}

\author{
Mohd Syakir Adli ${ }^{1}$, Noor Hazrin Hany Mohamad Hanif ${ }^{2}$, Siti Fauziah Toha Tohara ${ }^{3}$ \\ Mechatronics Department, Kulliyyah of Engineering, International Islamic University Malaysia, Malaysia
}

\begin{tabular}{|c|c|}
\hline Article Info & ABSTRACT \\
\hline & \multirow{8}{*}{$\begin{array}{l}\text { This paper presents a control scheme for speed control system in brushless dc } \\
\text { (BLDC) motor to be utilized for electric motorbike. While conventional } \\
\text { motorbikes require engine and fuel, electric motorbikes require DC motor } \\
\text { and battery pack in order to be powered up. The limitation with battery pack } \\
\text { is that it will need to be recharged after a certain period and distance. As the } \\
\text { recharging process is time consuming, a PID controller is designed to } \\
\text { maintain the speed of the motor at its optimum state, thus ensuring a longer } \\
\text { lasting battery time (until the next charge). The controller is designed to track } \\
\text { variations of speed references and stabilizes the output speed accordingly. } \\
\text { The simulation results conducted in MATLAB/SIMULINK® shows that the } \\
\text { motor, equipped with the PID controller was able to track the reference speed } \\
\text { in } 7.8 \times 10-2 \text { milliseconds with no overshoot. The result shows optimistic } \\
\text { possibility that the proposed controller can be used to maintain the speed of } \\
\text { the motor at its optimum speed }\end{array}$} \\
\hline Received Dec 21, 2017 & \\
\hline Revised Jan 22, 2018 & \\
\hline Accepted Feb 7, 2018 & \\
\hline Keyword: & \\
\hline BLDC motor & \\
\hline Speed controller & \\
\hline PID controller & \\
\hline
\end{tabular}

Copyright () 2018 Institute of Advanced Engineering and Science. All rights reserved.

\section{Corresponding Author:}

Noor Hazrin Hany Mohamad Hanif, Mecharonics Department, Kulliyyah of Engineering,

International Islamic University Malaysia,

Kuala Lumpur, Malaysia.

Email: noorhazrin@iium.edu.my

\section{INTRODUCTION}

Direct current motor (widely known as DC motor) has its own long history. This type of motor has been used in industries for many years. For about 150 years, direct current machines have showed their important role in electric drives [1]." This is due to their contributions in simple means and precise way of control for electrical machines. There are a lot of advantages that are related to their application in drives such as easy adjustment of rotational speed, uncomplicated start-up and reversal, stability in controlling small speed, fast response to change parameters in electric supply and many more [1]". Almost every mechanical element used nowadays in this era is accomplished by electric motors and one of them is DC motor.

Electric machine means the machine is converting electrical energy to mechanical energy [2]. It shows that the electric motor plays a huge role in human life. Electric motors come in various sizes; they have huge or small motor. Huge motor is a kind of motor that widely used in industry because of its capability to take loads of thousands of horsepower [2]. Some examples of huge motor application are elevators, electric trains, hoist, heavy metal rolling mills and etc. Besides, for small motor they are widely used in automobiles, robots, hand power tools and many more. All of these applications are very familiar and so important to human.

Direct current (DC) motor is very useful due to its capability in controlling the speed of the vehicles. It also has simple controlling system on the intrinsic decoupling between the flux and the torque. As the name given, brush dc motor uses brushes for its commutation then because of that it has some limitations of speed and lifetime [2]. However, brushless DC (BLDC) motor has been introduced to overcome this problem due to its physical speciality. Since BLDC motor do not require any brushes to operate, the risk of the motor to be worn out due to the brushes is eliminated, hence provide a longer motor lifetime [2]. This advantage 
make BLDC motor becomes famous and widely used in industry but since it is a non-linear system thus it needs more complicated speed controller than conventional DC motor.

Nowadays, BLDC motor is widely used in industry compared to brushed de motor. BLDC motor is a permanent magnet synchronous motor that controls armature currents by using position detectors and inverters in its operation [3]. This type of motor is not so different with any other conventional motors. It also has stator and rotor same like other motors. But the difference is, instead of using mechanical commutator as in the conventional motor, BLDC motor is electronically commutated which makes it virtually maintenance free motor [3]. BLDC motors are a derivative from used DC motor, brushed DC motor and they share the same torque and speed curve characteristics. BLDC motors exist in single phase, two phase and as well as three phase. Out of these, three phases motor is the most popular and widely used nowadays [3].

In this research work, we replaced the engine and transmission of a fuel powered motorcycle, the Honda CBR 250cc (Figure 2(a)) with the BLDC motor and batteries (Figure 2(b)). A speed controller that can maintain the motor to run at optimum speed with low power consumption is to be designed and developed. This is very useful to control the speed at its optimum state so that the users can reach their destination safely without worrying about battery draining.

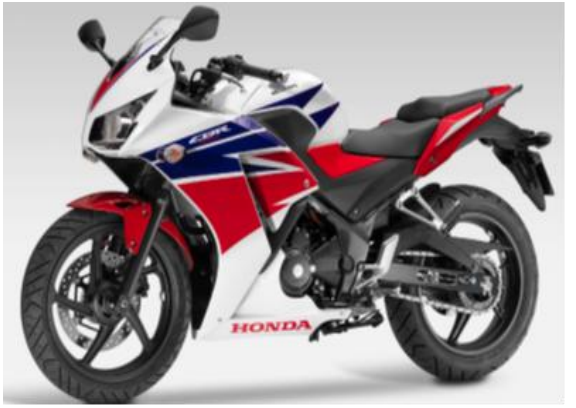

Figure 2(a). The original Honda CBR250cc (reproduced from [6])

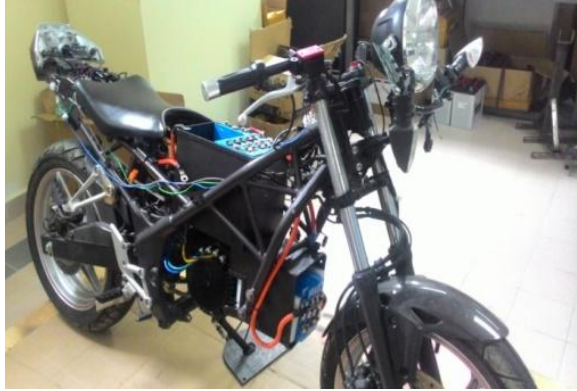

Figure 2(b). The retrofitted motorbike with the battery and BLDC motor

PID controller has been considered to control the speed of BLDC motor. PID controller consists of proportional, integral and derivative controller which has all the necessary dynamics such as fast reaction time, increase in control signal error towards zero and suitable to eliminate oscillation [4]. Meanwhile, the major changes of PID controller compared to PI controller is that PID controller increases the four characteristics of closed loop step response which are reducing rise time, reducing steady state error, reducing percentage overshoot and reducing settling time of the controller [4]. In this project, 14 sets of lithium iron phosphate (LiFePO4) batteries are used as the main source of energy for this electric motorbike.

\section{RESEARCH METHOD}

In this project, a $5 \mathrm{~kW}$ BLDC $48 \mathrm{~V}$ motor manufactured by Golden Motor Corporation has been used to run the electric motorbike (Figure 3). This motor is compact in design, uses fan air cooling as well as water resistant.

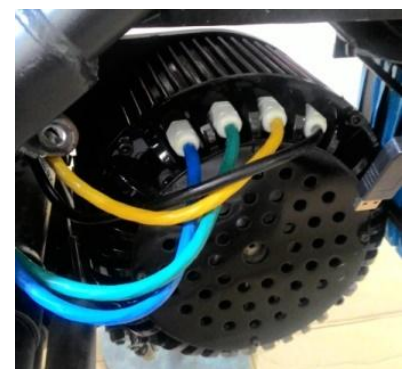

Figure 3. 5kW BLDC 48V motor 
Equation (1) shows the closed loop transfer function for speed control in BLDC motor derived in [5]. Vm is input motor voltage while $\omega_{\mathrm{m}}$ is the speed output of the motor. Kt and Ke represent torque and back emf constants respectively. Other parameters that are required for the transfer function are armature resistance, $R_{a}$, armature inductance $L_{a}$, viscous friction coefficient, B and rotor moment of inertia, $J$.

$$
\mathrm{G}(\mathrm{s})=\frac{\omega_{m}}{V m}=\left[\frac{K t}{L_{a} J s^{2}+\left(R_{a} J+L_{a} B\right) s+R_{a} B+K t K e}\right]
$$

The armature resistance $\left(\mathrm{R}_{\mathrm{a}}\right)$ and the armature inductance $\left(\mathrm{L}_{\mathrm{a}}\right)$ were obtained from the motor datasheet. The rotor moment of inertia, $\mathrm{J}$, was obtained by substituting the value of the mass, $\mathrm{m}(11 \mathrm{~kg})$ and radius, $\mathrm{r}(103 \mathrm{~mm})$ of the rotor to the following equation:

$$
J=0.5 m r^{2}
$$

The rest of the parameters were obtained by obtaining the angular velocity, $\omega$, when the system reaches steady-stae. This could be determined when the current, I, is constant. This information was also obtained from the motor datasheet. Using the motor rated voltage, E, of $48 \mathrm{~V}$, the rest of the parameters was determined using the following equations:

$$
\begin{aligned}
& E=I R+K t \omega \\
& B \omega=K t I
\end{aligned}
$$

Table 1 shows the physical parameters of the motor. Through substitutions of the obtained parameters into equation (6), the BLDC motor transfer function becomes:

$$
\mathrm{T}(\mathrm{s})=\frac{0.1693}{3.964 e-6 s^{2}+0.0003687 s+0.02933}
$$

Table 1. Parameters of BLDC motor

\begin{tabular}{cc}
\hline Parameters & Values \\
\hline Armature resistance, $\mathrm{R}_{\mathrm{a}}$ & $6.2 \mathrm{~m} \Omega$ \\
Armature inductance, $\mathrm{L}_{\mathrm{a}}$ & $68 \mu \mathrm{H}$ \\
Back emf constant, $\mathrm{K}_{\mathrm{e}}$ & $25.5 \times 10^{-3}$ \\
Torque constant, $\mathrm{K}_{\mathrm{t}}$ & $25.5 \times 10^{-3}$ \\
Viscous friction coefficient, B & 0.1072 \\
Rotor moment of inertia, $\mathrm{J}$ & 0.05834 \\
\hline
\end{tabular}

\section{RESULTS AND ANALYSIS}

In the MATLAB Simulink environment, the open loop system for BLDC motor speed controller was simulated. After starting the simulation, the curve is shown from the scope in Figure 4.

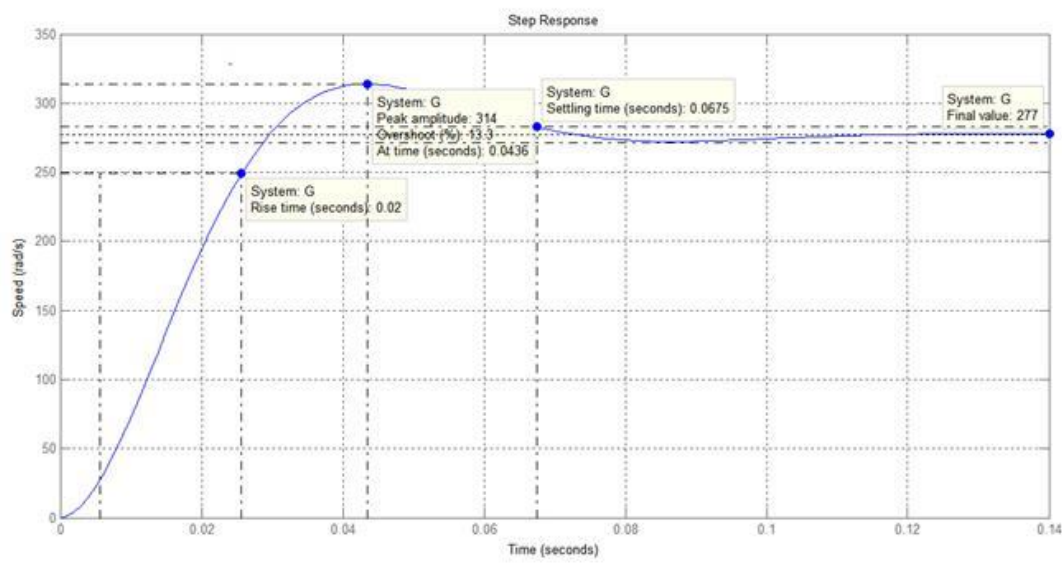

Figure 4. The step response of the open loop system 
Figure 4 shows the step response curve for open loop system of BLDC motor. It can be seen that the curve is not so good because it has the overshoot. Besides that, this curve also shows the steady state value for the motor speed which is $277 \mathrm{rad} / \mathrm{s}$. Therefore PID controller and a feedback were included into the system to improve the performance.

The block diagram of Figure 5 indicates the closed loop speed control system of BLDC motor. PID controller is used to control the performance of desired input speed before it goes to motor driver in order to drive the input so that the value is enough to run the motor at desired speed. The feedback system is used to decrease the error by comparing the output value with the desired one. To ensure the integration between the speed controller with the BLDC motor, a HPC $300 \mathrm{H}$ series motor driver is incorporated with the system.

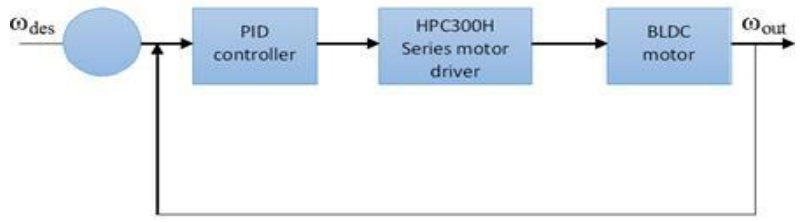

Figure 5. Block diagram of BLDC motor speed control system

The main reason the PID controller was chosen as it is used to correct the error between measured and reference values. The speciality of this controller is that it combines all Proportional (P), Integral (I) and Derivative (D) to make it a very efficient and stable system [6]. The output response of the BLDC motor with the cascaded PID controller was simulated in the Simulink environment, as shown in Figure 6. A step input of $48 \mathrm{~V}$ was provided to the controller and BLDC motor configuration in this simulation.

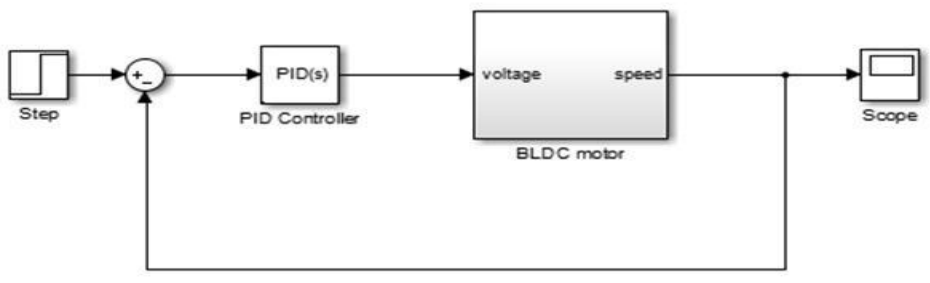

Figure 6. Closed loop system of BLDC motor by using Simulink

With the modified configuration, the output was observed as shown in Figure 7 and Figure 8.

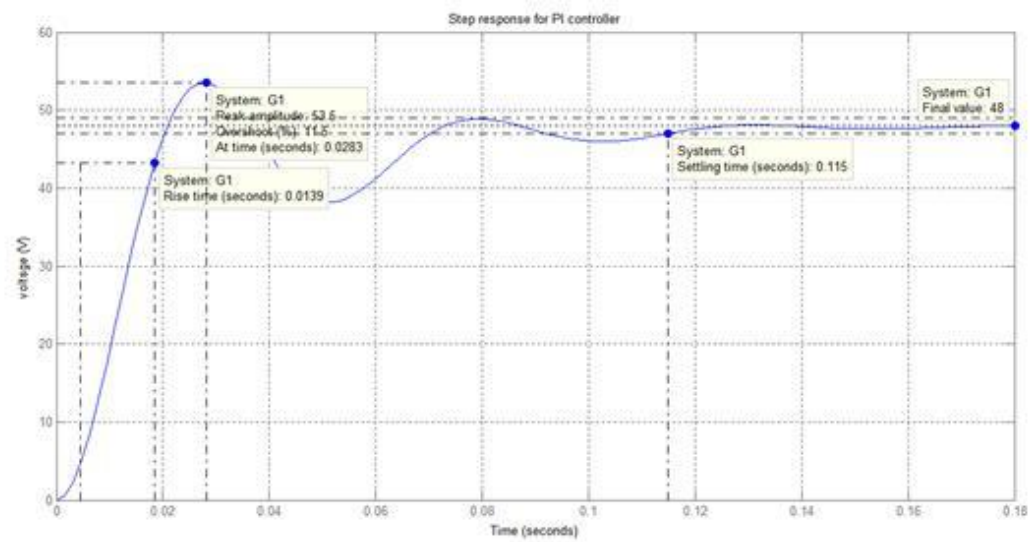

Figure 7. Closed loop curve (PI controller; $\mathrm{K}_{\mathrm{p}}=0.24568, \mathrm{~K}_{\mathrm{i}}=11, \mathrm{~K}_{\mathrm{d}}=0$ ) 


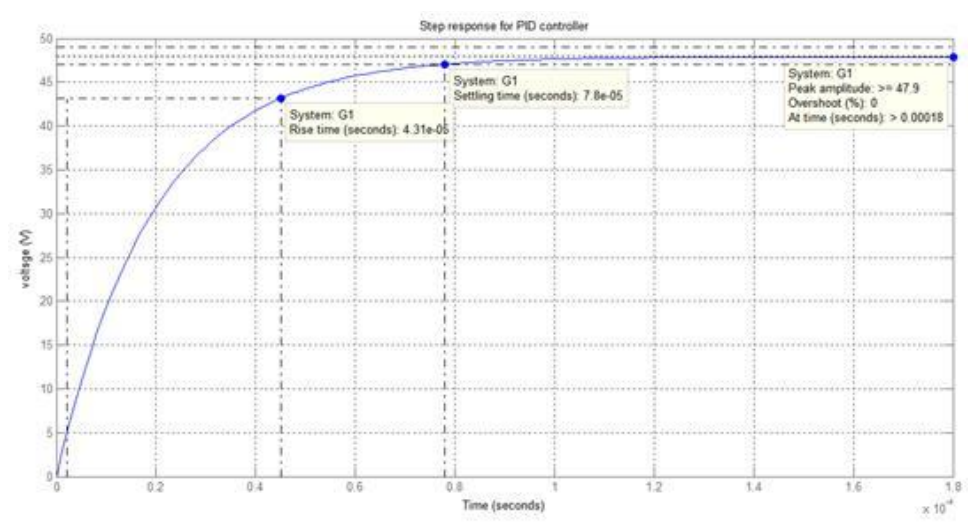

Figure 8: Closed loop curve (PID controller; $\mathrm{K}_{\mathrm{p}}=0.24568, \mathrm{~K}_{\mathrm{i}}=11$ and $\mathrm{K}_{\mathrm{d}}=1.2$ )

Figure 7 and Figure 8 show the step response for BLDC motor after adding PI controller and PID controller respectively. Both figures show the capability of the motor to reach its reference input which is 48 $\mathrm{V}$. The differences in their performances are being summarized to the table below.

Table 2. Parameters of transient response

\begin{tabular}{lccc}
\hline & Open loop & $\begin{array}{c}\text { Closed loop (PI } \\
\text { controller) }\end{array}$ & $\begin{array}{c}\text { Closed loop (PID } \\
\text { controller) }\end{array}$ \\
\hline Rise time & $0.02 \mathrm{~s}$ & $0.0139 \mathrm{~s}$ & $0.000043 \mathrm{~s}$ \\
Settling time & $0.0675 \mathrm{~s}$ & $0.1150 \mathrm{~s}$ & $0.000078 \mathrm{~s}$ \\
Percentage Overshoot & $13.27 \%$ & $11.52 \%$ & $0 \%$ \\
\hline
\end{tabular}

Table 2 shows the comparison between the transient response parameter for both open loop and closed loop system of BLDC motor. It could be observed that without the PID controller, the BLDC motor manage to achieve the optimum speed of the motor at $277 \mathrm{rad} / \mathrm{s}$, operating at $48 \mathrm{~V}$ within 67.5 milliseconds. However this rapid response produces a percentage overshoot of $13.27 \%$. This is considerably very high as it would result in sudden jerking motion that may cause discomfort to the riders, and to another extend, may risk in injury. The additional PI controller maintained the capability of speed tracking and slightly reduced the percentage overshoot.

The system was further improved with the integration of PID controller. The speed of the motor was preserved at its optimum speed and the percentage overshoot was completely eliminated. Although the response time slowed down to $7.8 \times 10^{-2}$ milliseconds, it is still deemed as a fast response. With this configuration, the capability of the motor to provide optimum speed could be achieved while assuring the comfort and safety of the riders.

Improvements of the motor performance could be further explored in terms of self-tuning capability such as works by [7] as well as different control algorithms [8-9]. The upgrades should be targeted to ensuring motor working at its optimal speed (hence reduce battery consumption) while taking into consideration its stability as well as performance errors. The comfort and safety of the riders should also be the utmost important factors in designing the motor controllers.

\section{CONCLUSION}

To conclude, PID controller can be considered as one the best controllers to control the speed of BLDC motor due to its capability on maintaining to the desired speed ( $277 \mathrm{rad} / \mathrm{s})$ at rapid transient response $\left(7.8 \times 10^{-2}\right.$ milliseconds). The integration of the controller also has provided an advantageous potential, which is guaranteeing user's safety and comfort. The next stage of this research work will be the integration between the motor controller and the BLDC motor itself. Speed analysis as well as estimation of battery state of charge and discharge will also be inverstigated at varying amount of loads. This research work has showcased the possibility of electrike motorbike as an alternative means of transportation in the near future. 


\section{ACKNOWLEDGEMENTS}

The authors would like to thank the IIUM Research Initiative Grant Scheme (RIGS16-071-0235) as well as Knowledge Transfer Project Grant (KTP15-010-0011) for funding this project.

\section{REFERENCES}

[1] Wach P. Brushless DC Motor Drives (BLDC). In: Dynamics and Control of Electrical Drives. Springer, Berlin, Heidelberg. 2011: 281-380.

[2] J. Griffin, "DC motors," Electronics and Power, 1982. 28(1), 109.

[3] S. Baldursson. BLDC Motor Modelling and Control - A Matlab / Simulink Implementation. MSc Thesis. University of Gothenburg; 2005.

[4] K. S. Rao and R. Mishra, "Comparative study of P, PI and PID controller for speed control of VSI-fed induction motor," Int. J. Eng. Dev. Res., vol. 2, no. 2, pp. 2321-9939, 2014.

[5] H. F. Prasetyo, A. S. Rohman, F. I. Hariadi, and H. Hindersah, "Controls of BLDC Motors in Electric Vehicle Testing Simulator," $6^{\text {th }}$ International Conference on System Engineering and Technology (ICSET), Bandung, pp. 173-178, 2016.

[6] O. J. Oguntoyinbo, PID Control of Brushless DC Motor and Robot Trajectory Planning Simulation with MATLAB/Simulink, B.IT Dissertation. Vaasa University of Applied Sciences; 2009.

[7] M.A. Abdel Ghany, et al. "A Novel Fuzzy Self-Tuning Technique of Single Neuron PID Controller for Brushless DC Motor”. International Journal of Power Electronics and Drive System (IJPEDS). 2017. 8(4): 1705-1713.

[8] Prita A., et al. "Comparative Study of Fuzzy Logic Based Speed Control of Multilevel Inverter fed Brushless DC Motor Drive”. International Journal of Power Electronics and Drive System (IJPEDS). 2014. 4(1): 70-80.

[9] Lei Jin-li, "Adaptive Control for Brushless DC Motor Based on Fuzzy Inference". TELKOMNIKA Indonesian Journal of Electrical Engineering. 2014. 12(5): 3392-3398.

\section{BIOGRAPHIES OF AUTHORS}

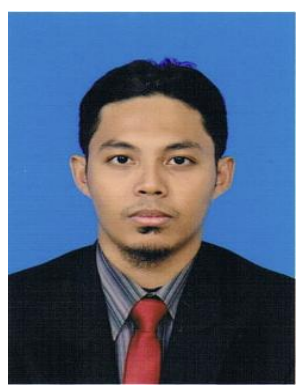

Muhamad Syakir Adli Sulaiman was born in Kuala Lumpur, Malaysia on $26^{\text {th }}$ of May 1994. He completed his degree in Bachelor of Mechatronics Engineering from faculty of engineering at International Islamic University Malaysia (IIUM) Gombak, Malaysia in 2017. He did research works on Brushless DC (BLDC) motor speed controller for electric motorbike as part of his final year project.

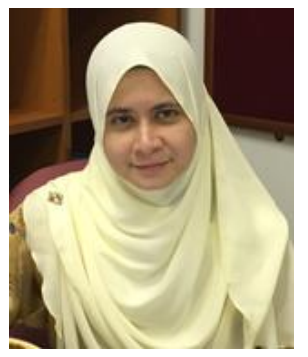

N.H.H. Mohamad Hanif received her B. Eng (Hons.) from Universiti Teknologi PETRONAS, Malaysia in 2002 and completed her MSc in Control Systems from Imperial College, London, U.K., in 2004. She was awarded the PhD degree in Electronics \& Computer Science from University of Southampton, U.K in 2016. She is currently an Assistant Professor at the Mechatronics Department, International Islamic University Malaysia. Her research interests include rehabilitation robotics, haptic technology, energy harvesting, wearable devices as well as instrumentation and control. Dr Hazrin is a member of IEEE, IET (The Institution of Engineering and Technology) as well as Board of Engineers Malaysia (BEM).

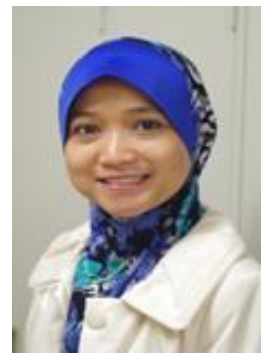

Siti Fauziah Toha is currently an Associate Professor at the Department of Mechatronics Engineering, International Islamic University Malaysia (IIUM). She received B. Eng (Hons) in Electrical and Electronics Engineering from University Technology Petronas and later received MSc from Universiti Sains Malaysia in electrical engineering. She then completed her Ph.D in Automatic Control and Systems Engineering from The University of Sheffield in 2010. Her current research interests are battery management system, energy reduction for electric motorcycle development as well as hybrid renewable energy applications using computational intelligence methods. Dr Toha is a senior member of IEEE and also a Professional Engineer in Malaysia as well as a Chartered Engineer with Engineering Council, The Institution of Engineering and Technology, United Kingdom. She is also an active member of Young Scientist Network, Academy of Sciences Malaysia (YSN-ASM). 